\title{
Analysis the influence of natural non-toxic components on physicochemical parameters of drilling fluids
}

\author{
A.I. Belukhin, R.Ya. Veliev, M.V. Vasyokha, A.A. Belozerov \\ Institute of Arctic Technology, Department of Marine Oil and Gas, Murmansk State Technical \\ University, Russian Federation
}

\begin{abstract}
Objective: to analyze the effect of non-toxic components on physical andchemical characteristics of drilling fluids. Methodology: determination of physical characteristics (density, plastic viscosity, yield point, effective viscosity, gel strength, water cut, mud cake thickness), determination of chemical characteristics (ph). results: threeudifferent drilling fluids were prepared, their physical and chemical characteristics were studied, a Comparative analysis was carried out, the impact on the marine ecosystem was assessed. Conclusions: the considered drilling fluids are competitive with others fluids used in well construction in terms of their physical and chemical properties, also the less damage to the environment is expected.
\end{abstract}

\section{Introduction}

The relevance of this topic is determined by the fact that drilling fluids are important components in the process of well construction. They perform a wide range of functions, from the removal of drilled rock to the surface and ending with the formation of a wall mud cake and lubrication of the drilling tool. In this regard, any drilling fluid must have an appropriate set of optimal indicators (parameters). Besides, in contact with rocks and the environment, modern drilling fluids must satisfy environmental safety requirements; also, they must have nondestructive effect on the ecosystem.

In the course of work, based on existing drilling fluid compositions, this research work developed alternative formulations using non-toxic plant components.

At present, there is a large number of different compounds, esters, and other biodegradable components that can be used as the basis for drilling fluids. All of them were developed to replace toxic drilling fluids created by using diesel fuel as a primary component. As a result of the extremely toxic effects on marine life, diesel fuel, as the basis for drilling fluids, was forbidden for exploitation in the Gulf of Mexico and the North Sea. Water-based drilling mud, although on-toxic, biodegradable, and relatively inexpensive, is not suitable for drilling complicated wells, especially in shale formations. Under such conditions, synthetic-based drilling fluid is preferable in shale drilling because of its ability to stabilize clay, high lubricity, less corrosion, less formation damage, minimal temperature effect, and lower cost. 
This issue was raised in the work of $[1,2]$. "Study of stability of invert emulsions based on vegetable oils". In their work, the authors investigate the possibility of using invert emulsion solutions (IESs) when drilling wells in difficult mining and geological conditions, drilling which using water-based solutions does not allow to achieve the required results and creates emergency situations that lead to accidents of technogenic and environmental nature. They discuss the advantages of IESs compared to water-based drilling fluids, including in terms of environmental impact.

Based on this work, [3, 4] conducted a more detailed study in the work "Environmental safety of invert-emulsion drilling fluids based on vegetable oils".

Based on the studies[5-7], it was decided to prepare drilling flushing fluids on the basis of vegetable oils and conduct a study of their physical and chemical properties and assess the impact of these drilling flushing fluids on the environment.

As a result, based on research data on modern, low-toxic drilling fluids, special formulations were developed that included natural non-toxic components, and experiments were carried out that made it possible to determine the following key parameters of the drilling fluid:
1) density
2) plastic viscosity
3) yield point
4) effective viscosity
5) gel strength
6) water cut
7) mud cake thickness
8) $\mathrm{PH}$.

\section{Materials and methods}

To determine the effect of low-toxicity components on the physical and chemical parameters of drilling fluids, several formulations have been developed in which a variety of toxic components have been substituted. Drillings fluids were prepared in lab beakers with total volume of $300 \mathrm{ml}$ using laboratory mixer Ofite $152-18-1$ at the speed of 11500 RPM.

The following characteristics of drilling fluids were analyzed: density, plastic viscosity, yield point, effective viscosity, gel strength, water cut, mud cake thickness, and $\mathrm{pH}$.

\subsection{Density}

Density was determined with a special cup balance scale, the characteristic was investigated by the following algorithm:

1. Place the mud scale on a horizontal surface.

2. Measure the temperature of the drilling fluid and record it in the appropriate drilling fluid $\log$.

3.Fill the dish with a drilling fluid sample.

4.Cover the dish with the cap and turn it slightly for a snug fit. Verify that some part of the drill sample comes out through the hole in the cap - this will indicate that the dish is full and free of air or gas.

5.Close the hole in the cover with your finger and rinse off any drilling fluid from the bowl and rocker arm. Then thoroughly dry all parts of the balance.

6. Place the scale on the base and move the slider weight along the outside of the rocker arm until the pan and rocker arm are in equilibrium, as indicated by the bubble level. 
7. Record the reading of the weight of the drill sample at the end of the reiter facing the bowl.

\subsection{Plastic viscosity}

Plastic viscosity was determined with anOFITE 800 8-Speed Electronic Viscometer.

Procedure for measuring plastic viscosity:

1. Place a sample of the freshly mixed drilling fluid into a thermos cup; the level of the fluid should coincide with the graduated line of the outer cylinder.

2. Heat or cool the sample fluid to the required temperature.

3. Switch on the electric motor by setting the switch to the "high speed" position and the gear lever to the lowest position. After waiting for the arrow to stabilize, record the measured parameter at a frequency of $600 \mathrm{rpm}$.

4. Set the gearbox shift lever to the position corresponding to the frequency of $300 \mathrm{rpm}$. After waiting for the arrow to stabilize, record the measured parameter at a frequency of $300 \mathrm{rpm}$.

5. The value of the plastic viscosity PV in centipoises corresponds to the difference between the readings of the instrument at a frequency of $600 \mathrm{rpm}$ and $300 \mathrm{rpm}$.

\subsection{Yield point}

The yield point was measured withan OFITE 800 8-Speed Electronic Viscometer.

Procedure for measuring a yield point:

1. Repeat steps 1-2 and 4 from paragraph 2.1

2. The yield point in $\mathrm{lb} / 100 \mathrm{ft}$ corresponds to the difference between the instrument reading at $300 \mathrm{rpm}$ and the plastic viscosity in centipoise.

\subsection{Effective viscosity}

The effective viscosity was measured withan OFITE 800 8-Speed Electronic Viscometer.

The procedure for measuring effective viscosity:

1. Repeat steps 1-3 from paragraph 2.1

2. The effective viscosity AV in cps is equal to the reading at $600 \mathrm{rpm}$ divided by 2 .

\subsection{Gel strength}

Gel strength was measured with an OFITE 800 8-Speed Electronic Viscometer. The measurements were taken after 10 seconds and 10 minutes according to the measurement method.

Gel strength measurement procedure:

1. Stir the fluid sample at $600 \mathrm{rpm}$ for approximately 15 seconds, then smoothly move the gearshift lever to neutral.

2. Switch off the electric motor, wait 10 seconds.

3. Set the switch to low speed, record the maximum deviation in $1 \mathrm{~b} / 100$ sq. feet corresponding to the initial shear stress. If the indicator needle does not return to zero after turning off the motor, its position should not be changed.

4. Repeat steps 1 and 2 with a 10 -minute wait. Then set the switch to low speed and record the deviation after 10 minutes and the temperature of the test fluid. 


\subsection{Water cut}

The water cut was determined withanOFITE filter press. After this experiment, the thickness of the filter cake of each fluid was determined.

Procedure for determining the water cut:

1. Provide a source of compressed gas at 6.9 bar.

2. Remove the bottom cover, pre-clean, and dry the cell. Insert the O-ring into the precleaned groove, turn the filling cell over. Close the filling hole with your finger.

3. Pour the sample into the cell at a level of $6.3 \mathrm{~mm}$ below the O-ring groove. Place a filter paper on the O-ring. Place the lid on the filter paper so that the flanges of the lid fit between the flanges of the cell, tighten the lid clockwise by hand. Turn the cell over, insert the container nipple into the sleeve connection of the filter press, and turn in any direction to fix it.

4. Place any graduated container under the drain to receive the filtrate.

5Open the inlet valve, apply pressure to the cell (when filling with compressed air, the pressure gauge needle starts to oscillate)

6. Typically, the API test lasts for 30 minutes. At the end of the test, close the valve, then shut off the compressed air supply. The pressure will be automatically bled off. Remove the cell.

7. Record the filtration volume $\mathrm{V}$ in milliliters.

8. Disassemble the cell, drain the fluid with maximum accuracy, remove the filter paper and remove excess drilling fluid from it, measure the thickness of the filter cake, record the result in millimeters.

\section{$2.7 \mathrm{pH}$}

The $\mathrm{pH}$ was determined with a laboratory $\mathrm{pH}$-meter SanXin PHS-3D-01. PH determination procedure:

1. Place the electrode in the fluid, wait for the readings to stabilize for 1 minute

2. Record the measured $\mathrm{pH}$ value and the type of the sample fluid (drilling fluid or filtrate)

3. Clean the electrode, place it in a storage container.

\subsection{Preparation of invert emulsion drilling fluid}

To determine the effect of low toxicity components on the physical and chemical parameters of drilling fluids, several formulations have been developed, in which a variety of toxic components have been replaced. The formulation of the initial solution is shown in Table 1.

Table 1. Hydrocarbon invert emulsion drilling fluid formulation.

\begin{tabular}{cc}
\hline Compound & Component composition, mass \% \\
\hline Diesel fuel & $37-39$ \\
Sulfonol & $4-6$ \\
Mineralized water (60\% CaCl solution) & $49-51$ \\
Clay powder & $3-4$ \\
Calcium Oxide & $3-4$ \\
\hline
\end{tabular}




\subsection{The preparation of invert emulsion drilling fluid based on corn oil}

In the formulation of the solution shown in Table 2, the hydrocarbon basic component was replaced with corn oil as a natural non-toxic component actively used and consumed by people in the process of cooking. Sulfonol emulsifier has a "hazard class 3" for human exposure, working processes with this reagent must be carried out using personal protective equipment and in rooms with supply and exhaust ventilation. Therefore, it was replaced by a solid water-insoluble emulsifier prepared independently in the laboratory.

Table 2. Corn oil-invert emulsion drilling fluid formulation.

\begin{tabular}{cc}
\hline Compound & Component composition, mass\% \\
\hline Mineralized water (15\% NaClsolution) & $29-29.5$ \\
Corn oil & $69-69.5$ \\
Emulsifier (aluminum stearate) & $0.2-0.4$ \\
Xanthan gum & $0.5-1$ \\
Gelatin & $0.3-0.6$ \\
& \\
\hline
\end{tabular}

To obtain a solid emulsifier, it is necessary to fill the crushed soap containing sodium stearate with water at $\mathrm{t}=40-45$ degrees Celsius and mix it until the foam appears, then add aluminum sulfate $\mathrm{Al}_{2}\left(\mathrm{SO}_{4}\right)_{3}$, until the foam $\mathrm{s}$ extinguishes. After that insoluble yellowwhite flakes will be formed; this chemical compound is the required emulsifier.

Xanthan gum, a food supplement E415, is a natural thickener, stabilizer, and structureforming agent. Gelatin is used as a gel-forming agent and forms thestructure; it is a product of the processing of connective tissue of animals, i.e., natural biopolymer. Mineralization of water occurs with the help of sodium chloride, i.e., white salt.

The process for preparing this drilling fluid is as follows:

1) Preparation of the water phase, its mineralization

2) Preparation of the oil medium, dissolution of the emulsifier

3) Adding a fluid-structure builder to the water phase

4) Emulsification of phases

5) Stabilization of the produced emulsion.

\subsection{Preparation of invert emulsified ester-based corn oil invert emulsion drilling fluid}

The process of preparing this drilling fluid consists of the following sequence:

1) Preparation of the water phase, its mineralization

2) Preparation of the oil medium, dissolution of the primary emulsifier

3) Adding a fluid-structure builder to the water phase

4) Emulsification of phases

5) Dissolution of the secondary emulsifier

6) Stabilization of the produced emulsion.

The differences in the formulation of Table 3 are that two emulsifiers were used to obtain a more stable emulsion, a solid one, which was used in the previous formulation, and a liquid one, obtained by carrying out an esterification reaction between ethyl ester and oleic acid. 
Table 3. Inverted emulsified ester-based corn oil invert emulsion drilling fluid formulation

\begin{tabular}{cc}
\hline Compound & Component composition, mass \% \\
\hline Mineralized water (15\% NaCl solution) & $38.7-39$ \\
Corn oil & $58-58.9$ \\
Primary emulsifier (ethyl ester of oleic acid) & $1.5-2$ \\
Secondary emulsifier (polyvalent soap) & $0.1-0.3$ \\
Xanthan gum & $0.5-1$ \\
\hline
\end{tabular}

\subsection{Preparation of clayless biopolymer drilling fluid with kelp (Laminaria)}

The formulation in Table 4 differs from the others in that it is not an emulsion-based fluid, but a water-based fluid. A polysaccharide biopolymer is used as a structure-forming agent, and crushed kelp (or Laminaria) is a source of alginic acid, a natural thickener, and a gelforming agent. Carboxymethyl cellulose (food supplement E469) was used to lower the filtration rate.

Table 4.Clayless biopolymer drilling fluid with kelp (Laminaria) formulation

\begin{tabular}{cc}
\hline Compound & Component composition, mass \% \\
\hline Mineralized water (15\% NaCl solution) & $97.6-98.4$ \\
Biopolymer & $1-1.5$ \\
Chopped kelp (Laminaria) & $0.2-0.3$ \\
Carboxymethylcellulose & $0.2-0.3$ \\
Xanthan gum & $0.2-0.3$ \\
\hline
\end{tabular}

\section{Results and discussions}

\subsection{Density}

The density of the drilling fluid is determined by measuring the mass of a certain volume of the fluid or using special lever scales. The density of the fluid is presented in Figure 1. 


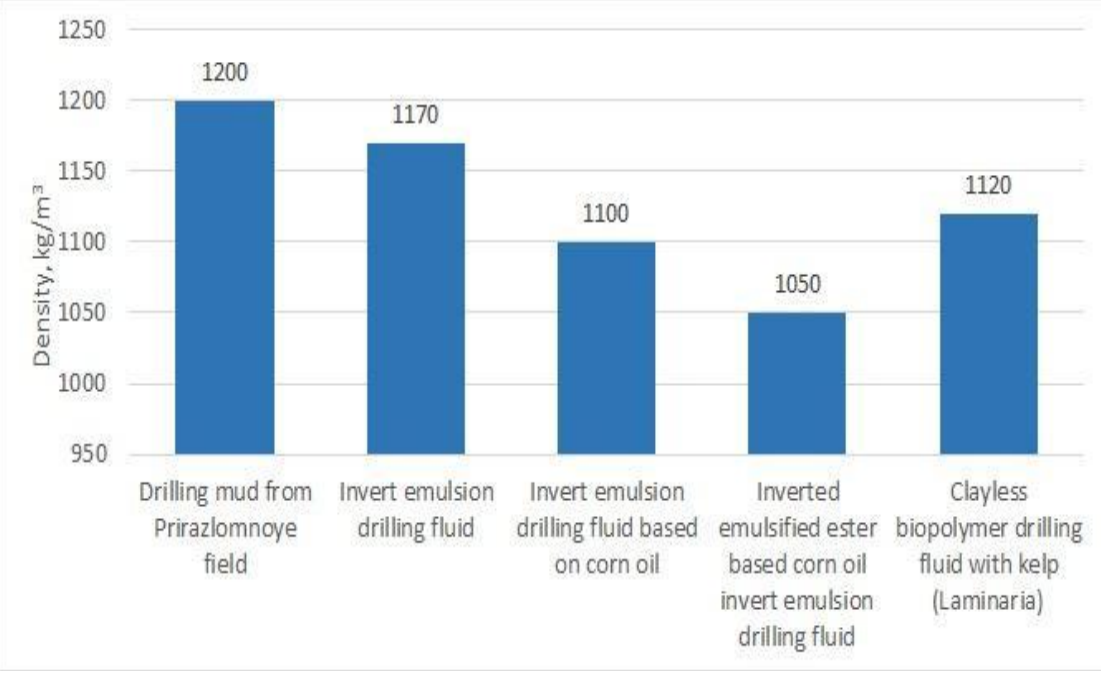

Fig. 1. Density.

\subsection{Plastic viscosity}

The plastic viscosity of drilling fluids was measured using an OFITE 800 8-Speed Electronic Viscometer. The viscometer readings were recorded, the plastic viscosity of the fluid is presented in Figure 2.

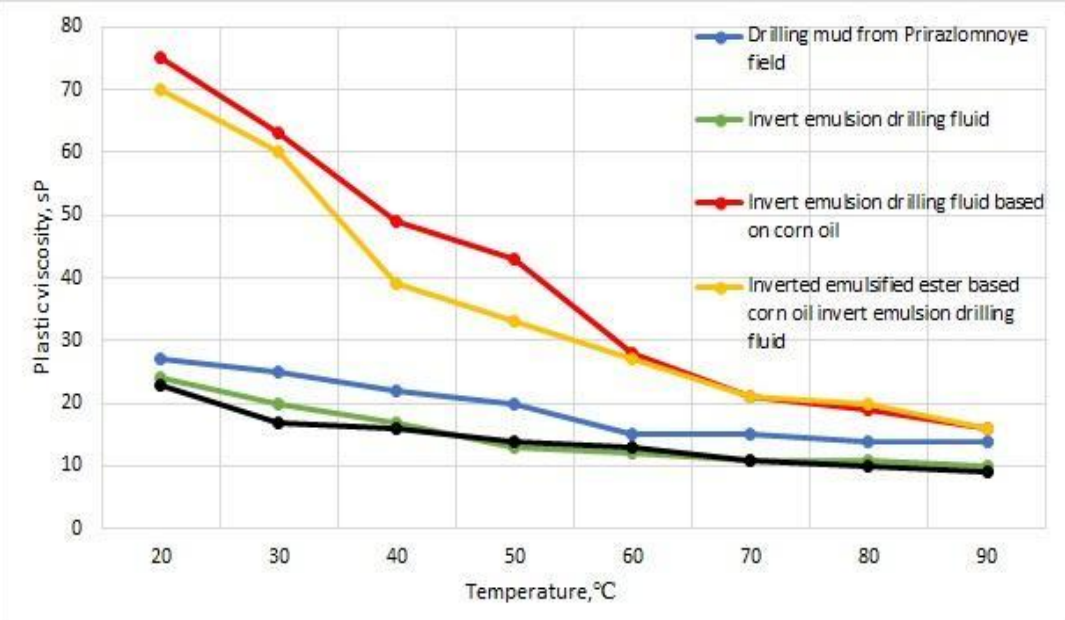

Fig. 2. Plastic viscosity.

\subsection{Yield point}

The yield point was measured using an OFITE 800 8-Speed Electronic Viscometer. The yield point of the fluid is presented in Figure 3. 


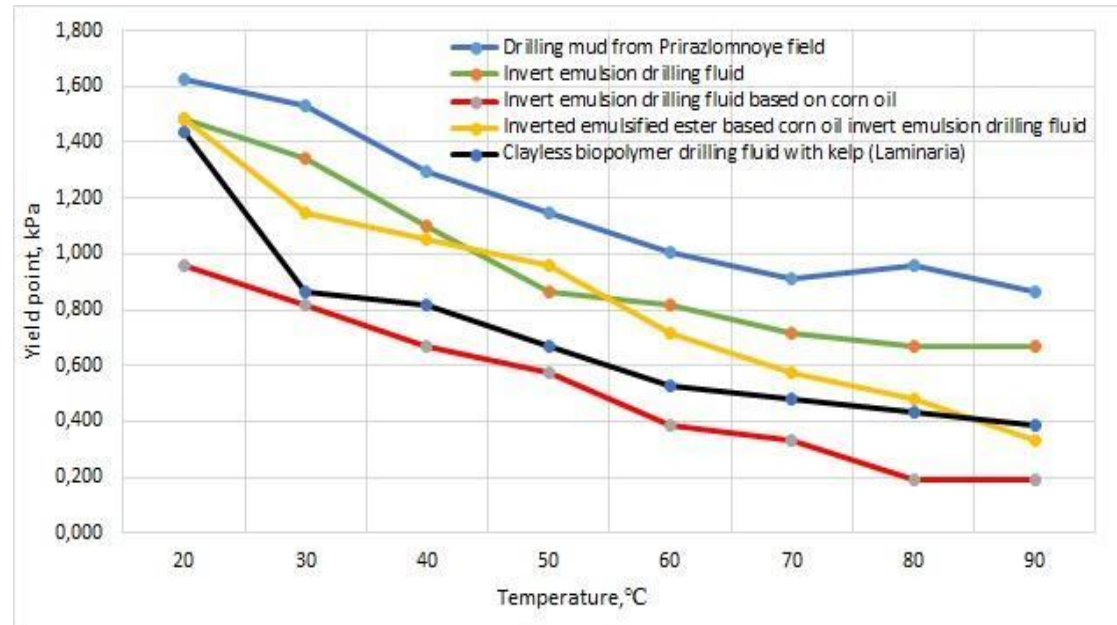

Fig. 3. Yield point.

\subsection{Effective (apparent) viscosity}

The effective (apparent) viscosity was measured using an OFITE 800 8-Speed Electronic Viscometer. The effective (apparent) viscosity of the fluid is presented in Figure 4.

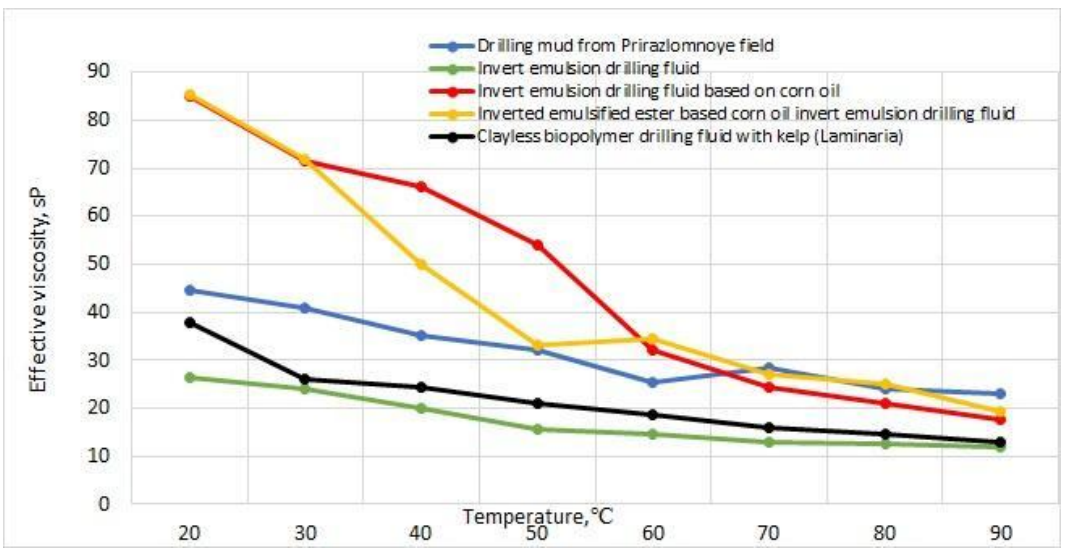

Fig. 4. Effective (apparent) viscosity.

\subsection{Gel strength}

Gel strength is measured using the OFITE 800 8-Speed Electronic Viscometer. The gel strength of the fluid is shown in Figures 5 and 6 . Measurements were carried out after 10 seconds and 10 minutes according to the measurement procedure. 


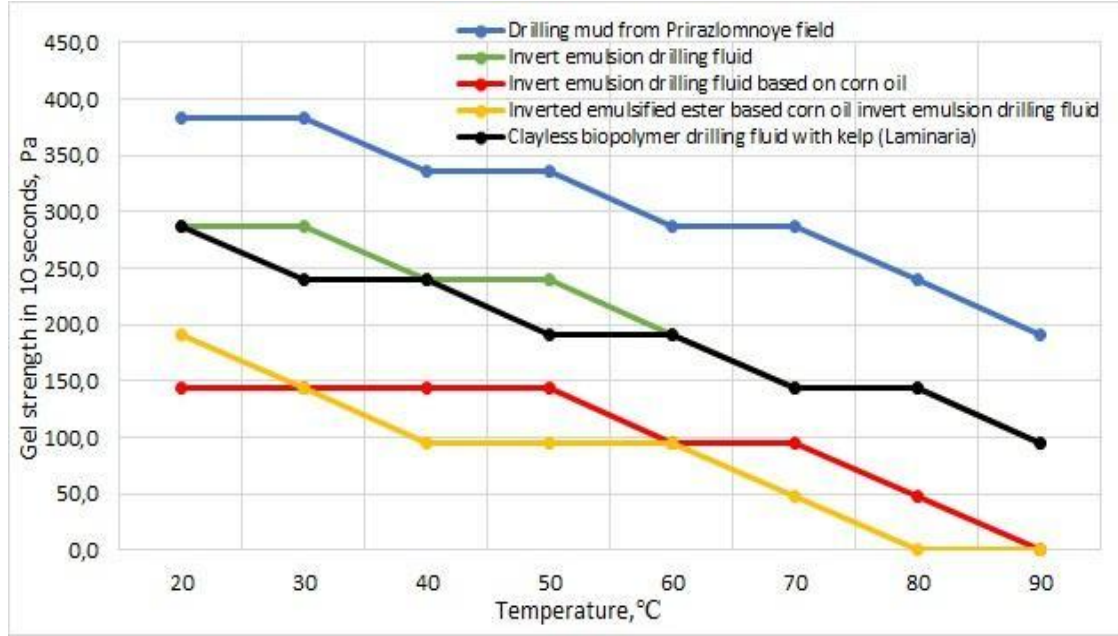

Fig. 5. Gel strength after10 seconds

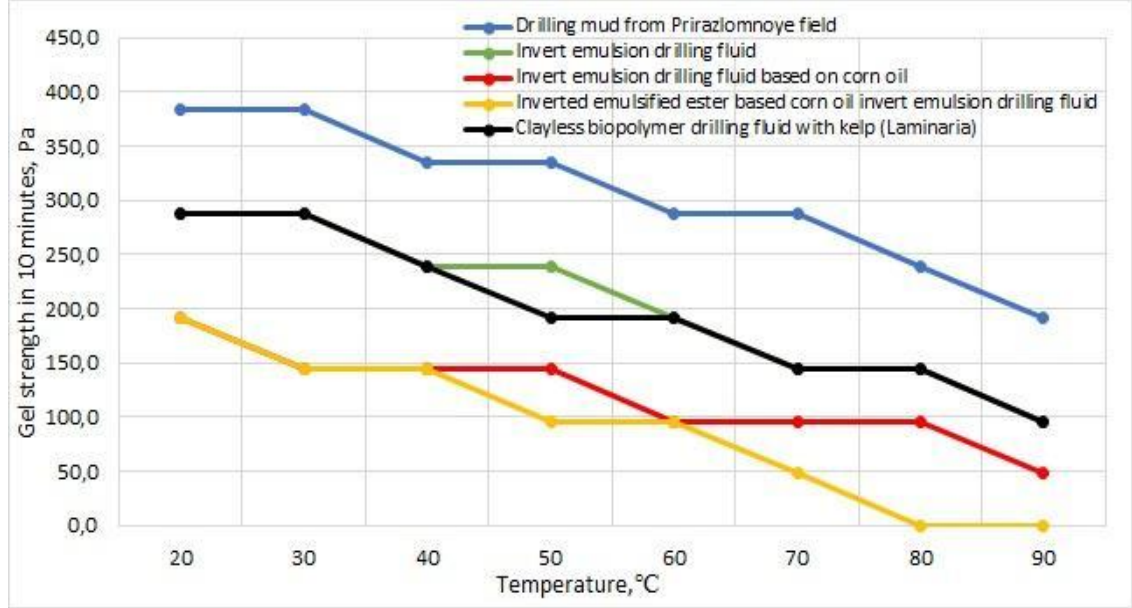

Fig. 6. Gel strength after10 minutes.

\subsection{Water cut}

The water cut was determined using the OFITE filter press. The water cut of the fluid is in Figure 7. 


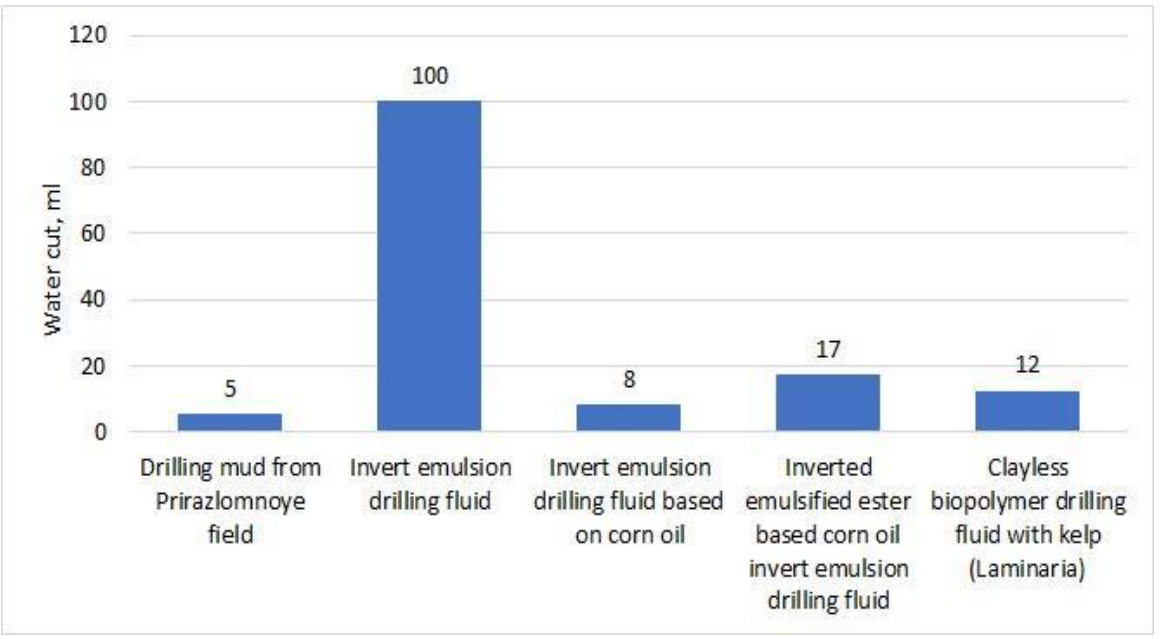

Fig. 7. Water cut.

\subsection{Toxic influence of drilling fluids on the marine environment}

After this experiment, the thickness of the mud cake of each fluid was determined. The measurement results are shown in Figure 8.

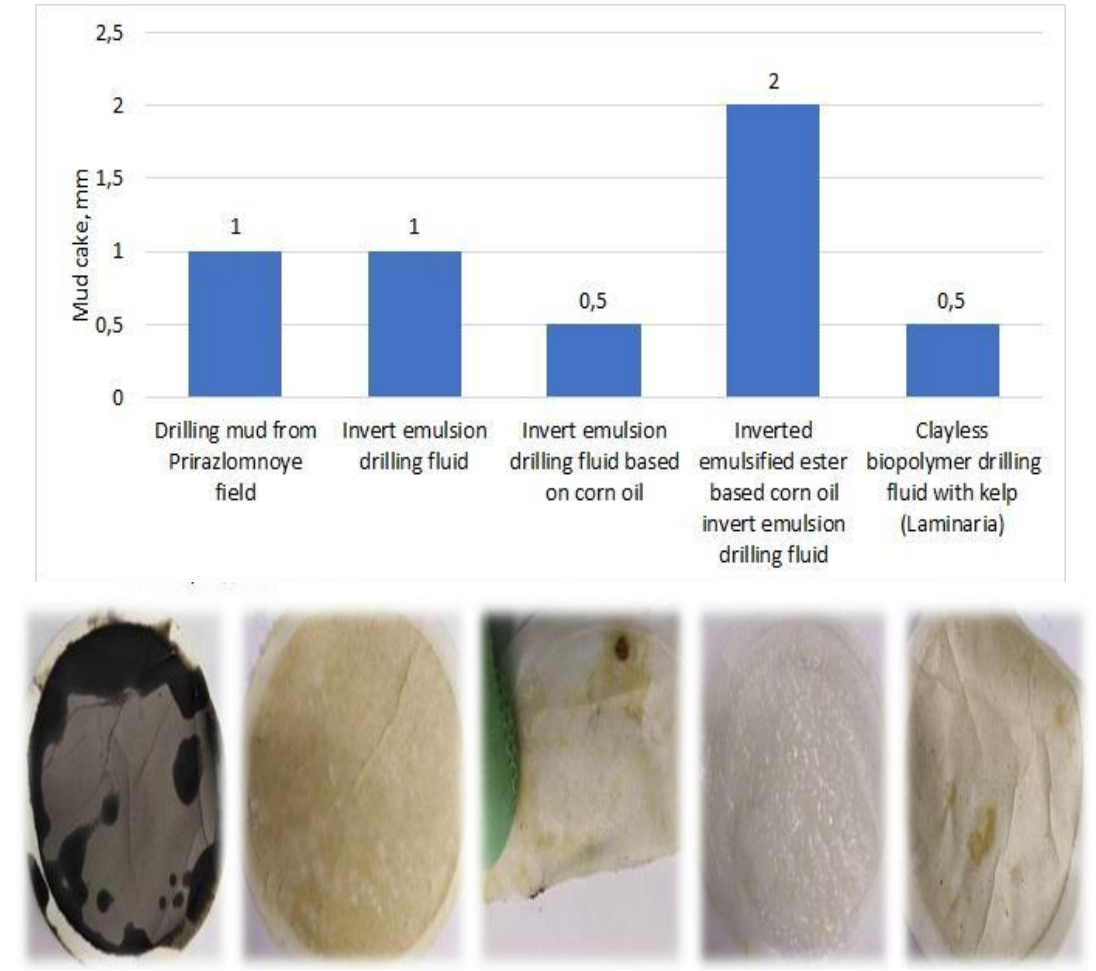

Fig. 8. Mud cake. 


\subsection{The toxic influence of drilling fluids on the marine environment}

When estimating the environmental impact of drilling fluids, one of the three most important indicators is the rate of biodegradation, i.e., the ability to decompose in natural conditions under the influence of microorganisms (the total amount of gases released during the decomposition; the rate of biodegradation, the rate of deposition).

Marine mussels of the mytilusedulis family, which live on the coast of the Barents Sea, were chosen as indicators showing the degree of influence of fluids on the marine ecosystems. The research works were carried out as follows: several colonies of mussels in seawater were placed in a special cabinet that creates the temperature of seawater in the summer (approximately 5-7 degrees Celsius). Then, $10 \mathrm{ml}$ of prepared solution were added to each of the samples. Then, within a few days, deaths were recorded. The research results are presented in Figure 9.

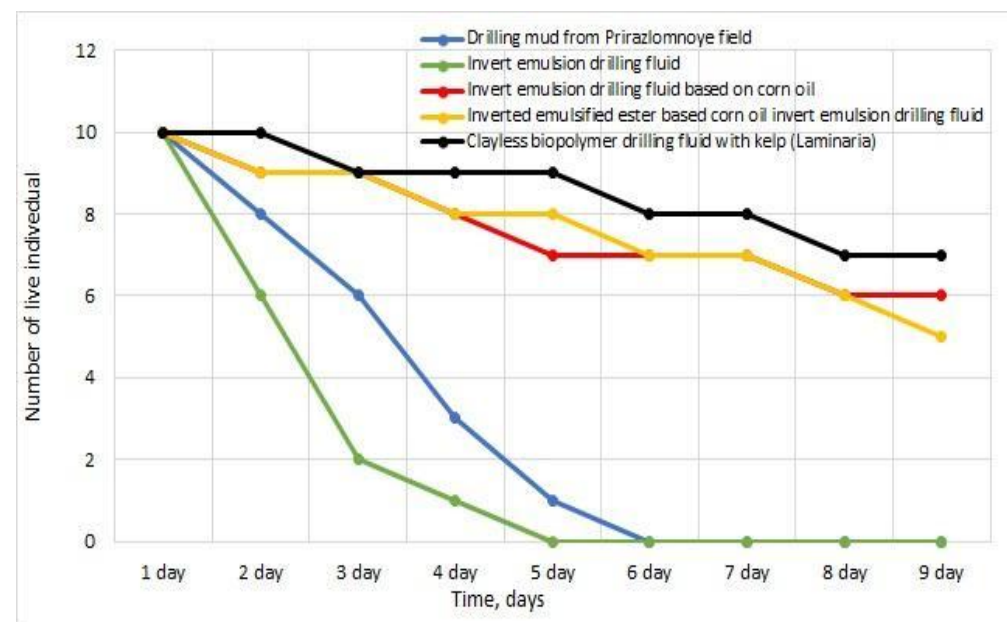

Fig. 9. Results of toxic effects on mussels of the mytilusedulis family.

\section{Conclusions}

In the course of laboratory tests, a complex of studies of qualitative parameters of different drilling fluids formulations was carried out. As a result of comparative analysis, the following conclusions were made:

1) Drilling fluid based on vegetable oils in terms of density is close to water-based fluids.

2) Plastic viscosity of investigated oil-based fluids is higher than that of other investigatedfluids in a wide range of temperatures. This fact favorably affects the amount of drill cuttings carried to the near-surface zone.

3) Oil-based drilling fluids have good lubricating properties, which, in its turn, can ensure the longevity of the drilling tool.

4) The strength of the corn oil-based fluid gel has the lowest values of all the samples tested.

This parameter allows us to conclude that as a result of the start of well exploitation, the circulation flow will create less stress on the drill string, which, in its turn, will reduce the

Likelihood of accidents. 


\section{References}

1. F.N. Yangirov, D.R. Sultanov, A.V. Chudnovskaya, Inhibited solution recipe for active clays drilling,Development and operation of oil and gas fields, 1(117): 29-36(2019).

2. A.V. Chudnovskaya,R.M. Khasanov, R.R. Valiev, Environmental safety of application of invert-emulsion drilling fluids based on vegetable oils,Oil and Gas Business,6: 7080 (2016).

3. A.V. Chudnovskaya,T.D. Dikhtyar, F.N.Yangirov,Study of the stability of invert emulsions based on vegetable oils. Improving the quality of well construction,II international scientific and technical conference dedicated to the memory of Mavlyutov,259-261.(2010).

4. Wei-Tao Wu,Massoudi Mehrdad,Heat Transfer and Dissipation Effects in the Flow of a Drilling Fluid,Fluids, 1(2016).

5. Y.H. Chai,S.Yusup,V.S. Chok, S. Irawan,J.D.B. Singh, B.L.F. Chin. Comparison of rheological properties of graphene/carbon nanotube hydrogenated oil-based biodegradable drilling fluid.IOP Conference Series: Materials Science and Engineering, 206 (2017).

6. F.N. Yangirov. Development of an inhibited solution formulation for drilling active clays. OFI Testing Equipment. (2020).

7. E.I. Chernykh, A.S. Shestakov, T.N. Poyarkova, K.V. Ilyushina, A.V. Falaleyev Emulsifiers of reverse emulsions based on monoethanolamides of fatty acids of vegetable oils, Vestnik VSU, series: Chemistry. Biology. Pharmacy. (2016) 